Editorial

\title{
Critical Perspectives on Digital Literacies: Creating a Path Forward
}

\author{
Hiller A. Spires \\ Department of Teacher Education and Learning Sciences, North Carolina State University, Raleigh, NC 27695, USA; \\ E-Mail: haspires@ncsu.edu
}

Submitted: 30 April 2019 | Published: 11 June 2019

\begin{abstract}
This thematic issue of Media and Communication features a range of critical perspectives on digital literacies with the aim of shedding light on a path forward with respect to theory, research and practice. The issue hosts fourteen articles divided into four themes that address digital literacies in varying ways. The four themes are (a) defining digital literacies, (b) socio-cultural theories of digital literacies, (c) digital literacies in practice, and (d) digital skills and efficacy. The articles make a strong case for the continued exploration of the significance and (re)definition of digital literacies within our global communicative landscape. The authors have inspired new dialogue, research directions, innovative practices, and policy on digital literacies. As digital technologies continue to evolve so too will intellectual frameworks-generating nuance and scope for and by researchers as well as practitioners.
\end{abstract}

\section{Keywords}

critical perspectives; digital literacies; digital media; socio-cultural theory

\section{Issue}

This editorial is part of the issue "Critical Perspectives on Digital Literacies: Creating a Path Forward", edited by Hiller A. Spires (North Carolina State University, USA).

(C) 2019 by the author; licensee Cogitatio (Lisbon, Portugal). This article is licensed under a Creative Commons Attribution 4.0 International License (CC BY).

\section{Introduction}

Many would agree there is no consensus on a model or framework for digital literacies that adequately meet the demands of our contemporary global society. Academics typically resist both utopian and dystopian perspectives on digital literacies models so as not to limit their transformative potential. With that caveat in mind, one way to think about digital literacies is to organize the related cognitive and social processes into three categories: (a) locating and consuming digital content; (b) creating and curating digital content; and (c) communicating digital content (Spires \& Bartlett, 2012). It is essential to make judgments about when and how to apply information to solve problems and share new knowledge. Most importantly, digital literacies exist within sociocultural contexts that give them shape and definition.

Learning happens everywhere and all the time. With the growing emphasis of digital frames of reference and tools what we learn can be amplified and shared globally in an instant. The repercussions of this phenomena are hard to grasp and even more challenging to conceptualize in a clear, compelling fashion. Russian theorist, Vygotsky's (1978) sociocultural theory of learning situates digital literacy and learning. Vygotsky's view of learning stems from social interactions between humans and the learning that transpires. His theory still applies to contemporary settings in which learning takes place when humans interact with digital technologies.

More than ever before, contemporary life is mediated by digital technologies and frames of reference. The same digital advances that enhance our work and social life also challenge our social norms, creating a constant recalibration of our sensibilities surrounding digital literacies. Challenges notwithstanding, digital literacies expertise should be positioned as a prerogative for all humans, which ultimately supports full participation in a global society.

This thematic issue of Media and Communication features articles on digital literacies from a variety of domains (i.e., communication, education, psychology, linguistics). Likewise, the articles target multiple audiences, 
including educational practitioners, theoreticians, and researchers. Digital literacies is a growing area of scholarship and one that is marked by ambiguity, nuance, and promise-primarily because technology shifts faster than society and the educational sector can. Leu and his colleagues (Leu et al., 2015) used the term deictic to refer to the changing nature of literacy, which is prompted by constantly evolving technologies within our society. By all accounts, technological changes will continue since the total number of Internet users is over 4 billion worldwide and growing.

This thematic issue focuses on critical perspectives of digital literacies for two reasons. First, within the digital world, it is essential to comparatively scrutinize information in terms of its credibility and reliability due to the open-ended nature of internet authorship. Second, critical perspectives designate the inherent social advantages and disadvantages afforded by access to and usage of digital technologies and information within our global society. As we consume and construct digital texts it is essential to understand socially constructed concepts, such as power, inequality, and injustice in human relationships. Above all, human agency is at the core of what it means to be digitally literate.

\section{Contributions in This Thematic Issue}

This thematic issue presents a range of critical perspectives on digital literacies with the aim of shedding light on a path forward with respect to theory, research and practice. The issue hosts fourteen articles divided into four themes that address digital literacies in varying ways. The four themes are (a) defining digital literacies, (b) sociocultural theories of digital literacies, (c) digital literacies in practice, and (d) digital skills and efficacy.

\subsection{Defining Digital Literacies}

For the first theme of defining digital literacies, Leaning (2019) opens the thematic issue by arguing that integrating media and information literacy provides a sophisticated definition as well as direction for digital literacy. Nichols and Stornaiuolo (2019) propose a multidimensional framework for understanding digital literacies. Engaging assemblage theory, the authors explore current articulations of digital literacy as well as those that have been discarded. They invite the field to consider the "assemblage" of digital literacies to create a new research path. Godhe (2019) targets the curricula in Sweden, Denmark, Finland, and Norway and compares and contrasts how digital literacy and digital competence are interpreted within school contexts. Finally, Lee, Park, Jang and Cho (2019) adopt the idea of theoretical triangulation in interpretive inquiry to explore how multiple perspectives (i.e., sociocultural, affective, and cognitive) can articulate the intricacies of youth's digital literacy practices.

\subsection{Socio-Cultural Theories of Digital Literacies}

For the second theme, socio-cultural theories of digital literacies, Lund, Furberg and Gudmundsdottir (2019) consider digital literacies as agentic and transformative through an empirical study on how lower secondary students engage digital and other resources as they encounter science problems. In another empirical study, Pawluczuk, Webster, Smith and Hall (2019) explore the ways digital youth workers perceive and evaluate the social impact of their work. Taking a markedly different stance, Bali (2019) re-imagines digital literacies in general as well as teaching digital literacies (i.e., consuming, producing and communicating) through the critical feminist perspective presented in Women's Ways of Knowing.

\subsection{Digital Literacies in Practice}

Moving to the third theme of digital literacies in practice, these articles engage the reader with practices in four different contexts. Watt (2019) shares a two-year, funded, qualitative inquiry on the challenges and possibilities of integrating video production into pre-service teacher education as a critical digital literacy practice. This includes the skills, knowledge, and dispositions that lead to the ability to critique and create digital texts that interrogate the self, the other, and the world. Next Yue, Nekmat and Beta (2019) argues that Southeast Asian youth digital citizenship foregrounds civic participation as emergent acts that not only serve to improve society but also foregrounds new ways of civic-making in Southeast Asian societies. Hagerman (2019) offers a critical review of the designs, impacts, and markers of quality of six literacies interventions, which offers new insights into the strengths and weaknesses of fixed and open approaches to literacies. Finally, Yuan, Wang and Eagle (2019) first define and conceptualize ELL learning, establish a shared vision of digital literacies, and review the literature on how practices of digital literacies empower ELL students to become active learners.

\subsection{Digital Skills and Efficacy}

In the last theme, digital skills and efficacy, Berger and Wolling's (2019) study investigates factors that associate with teachers' practice of fostering students' digital protective skills. Next, Banzato and Coin (2019) conducted workshops that taught eighteen children about multimodal approaches to narration. The authors concluded that it is possible to positively impact students' selfefficacy about their narrative skills. Finally, Riesmeyer, Hauswald and Mergen (2019) explore how girls receive nutritional advice through Instagram, concluding that there is a positive relationship among media and health literacy, identity, and food-related behaviors.

In summary, authors from four continents (nine countries) make the case that digital literacy has had-and is continuing to have-an impact on contemporary educa- 
tion as well as society at large. The authors have inspired new dialogue, research directions, innovative practices, and policy on digital literacies. As digital technologies continue to evolve so too will intellectual frameworksgenerating nuance and scope for and by researchers as well as practitioners.

\section{Acknowledgments}

Hiller A. Spires would like to thank Cátia Simões and António Vieira in the editorial office of Media and Communication for their support. Also, acknowledgment goes to Jessica Eagle, a PhD student at North Carolina State University, for her editorial assistance throughout the process.

\section{Conflict of Interests}

The author declares no conflict of interests.

\section{References}

Bali, M. (2019). Reimagining digital literacies from a feminist perspective in a postcolonial context. Media and Communication, 7(2), 69-81.

Banzato, M., \& Coin, F. (2019). Self-efficacy in multimodal narrative educational activities: Explorative study in a multicultural and multilingual Italian primary school. Media and Communication, 7(2), 148-159.

Berger, M., \& Wolling, J. (2019). They need more than technology-equipped schools: Factors associated with teachers' practice of fostering students' digital protective skills. Media and Communication, 7(2), 137-147.

Godhe, A. L. (2019). Digital literacy or digital competence: Conceptualizations in Nordic curricula. Media and Communication, 7(2), 25-35.

Hagerman, M. S. (2019). Digital literacies learning in contexts of development: A critical review of six IDRCfunded interventions 2016-2018. Media and Communication, 7(2), 115-127.

Leaning, M. (2019). An approach to digital literacy through the integration of media and Information literacy. Media Communication, 7(2), 4-13.

Lee, K. M., Park, S., Jang, B. G., \& Cho, B. Y. (2019). Mul- tidimensional approaches to examining digital literacies in the contemporary global society. Media Communication, 7(2), 36-46.

Leu, D. J., Forzani, E., Rhoads, C., Maykel, C., Kennedy, C., \& Timbrell, N. (2015). The new literacies of online research and comprehension: Rethinking the reading achievement gap. Reading Research Quarterly, 50(1), 37-59.

Lund, A., Furberg, A., \& Gudmundsdottir, G. B., (2019). Expanding and embedding digital literacies: Transformative agency in education. Media and Communication, 7(2), 47-58.

Nichols, P., \& Stornaiuolo, A. (2019). Assembling "digital literacies": Contingent pasts, possible futures. Media and Communication, 7(2), 14-24.

Pawluczuk, A., Webster, G., Smith, C., \& Hall, H. (2019). The social impact of digital youth work: What are we looking for? Media and Communication, 7(2), 59-68.

Riesmeyer, C., Hauswald, J., \& Mergen, M. (2019). (Un)healthy behavior? The relationship between media literacy, nutritional behavior, and self representation on Instagram. Media and Communication, 7(2), 160-168.

Spires, H., \& Bartlett, M. (2012). Digital literacies and learning: Designing a path forward (Friday Institute White Paper Series, No. 5). Raleigh, NC: North Carolina State University. Retrieved from https://www. fi.ncsu.edu/wp-content/uploads/2013/05/digitalliteracies-and-learning.pdf

Vygotsky, L. (1978). Mind in society: The development of higher psychological processes. Cambridge, MA: Harvard University Press.

Watt, D. P. (2019). Video production in elementary teacher education as a critical digital literacy practice. Media and Communication, 7(2), 82-99.

Yuan, C., Wang, L., \& Eagle, J. (2019). Empowering English Language Learners students through digital literacies: Research, complexities, and implications. Media and Communication, 7(2), 128-136.

Yue, A., Nekmat, E., \& Beta, A. R. (2019). Digital literacy through digital citizenship: Online civic participation and public opinion evaluation of youth minorities in Southeast Asia. Media and Communication, $7(2), 100-114$.

\section{About the Author}

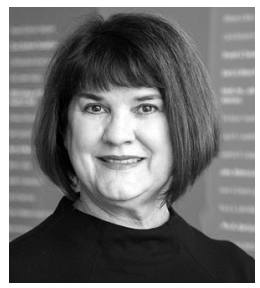

Hiller A. Spires is an Alumni Distinguished Graduate Professor of Literacy and Technology at North Carolina State University, where she leads the New Literacies \& Global Learning program. Dr. Spires studies the integration of emerging technologies in order to illustrate research-based, best practices for digital literacy learning. She is the founding director of The Friday Institute for Educational Innovation. Dr. Spires recently helped create Suzhou North America High School in China and currently serves as honorary principal. 